\title{
Thermodynamic Analysis of Effects of the Inlet Air Cooling on Cycle Performance in Combined Brayton- Diesel Cycle
}

\author{
Betul Sarac $^{1}$ (i) Teoman Ayhan $^{2}$ (iD) \\ ${ }^{1}$ Karadeniz Technical University, Department of Naval Architecture and Marine Engineering, Trabzon, Turkey \\ ${ }^{2}$ Avrasya University, Department of Mechanical Engineering, Trabzon, Turkey
}

\section{A B S T R AC T}

T $\mathrm{n}$ the present study, the effects of inlet air cooling on compound cycle performance in a 1 diesel gas turbine engine system where waste heat is used in the composite power system in the sustainable energy system were investigated thermodynamically. The effects of the inlet air cooling the system that enhances power production and the resulting thermal efficiency values were analyzed based on various operational variables (gas turbine pressure ratio, diesel engine compression ratio, gas turbine inlet and fresh air inlet temperatures, etc.). The energy losses in each system component were determined and the second law efficiency of the system was determined based on the introduced operational parameters. The gas turbine unit in the model included a gas generator with two compressors and a high-pressure turbine, and a low-pressure power turbine running on a separate shaft. The diesel engine and gas-generator exhaust gases were mixed and expanded in a low-pressure turbine, leading to the production of power with the waste energy. In the cycle, an intake air cooler, an intercooler and a recuperative air pre-heater were used. In the intake air cooling cycle, the power increase was around $15 \%$ when the pressure rate of the low-pressure compressor was 3.5. Natural gas was used as fuel in the thermodynamic model. The cycle irreversibilitywas used in the calculations based onthe thermodynamic concepts.

\section{Keywords:}

Brayton-diesel cycle, Combined power system, Energy, Exergy

\author{
Article History: \\ Received: 2020/01/14 \\ Accepted: $2020 / 01 / 30$ \\ Online: $2020 / 03 / 26$ \\ Correspondence to: Betül Saraç, \\ Department of Naval Architecture and \\ Marine Engineering, Karadeniz Technical \\ University, 61530, Trabzon, Turkey. \\ E-mail:bsarac@ktu.edu.tr, \\ Phone: +5353972703 , \\ Fax: +4627522158 .
}

\section{INTRODUCTION}

$\mathrm{T}$ he contribution of energy in ensuring the sustainability of modern life is a primary requirement. Today, energy technologies are advancing towards the use of clean energy resources. However, it is observed that it would take long years to develop the technologies that could be adequate for global energy requirements [1]. Today, energy conversion technologies based on fossil fuels are used in power generation and to fulfill power requirements. Due to the development of energy conversion technologies based on fossil fuels, the importance of composite cycles in the reduction of exhaust emissions released to the environment per unit of generated electrical energy and the thermal efficiency of the system has increased. The combined power cycles for high efficiency and reduction of negative effects on the environment have led to the consideration of combined power cycles as ideal conventional power systems $[2,3]$.
The combined power systems are also commonly applied in power propulsion systems of high tonnage ships $[4,5,6]$. The fact that natural gas could be used as fuel in combined power systems led to the development of other thermodynamic power cycles that work with diesel-based combined power cycle systems [7]. In gas turbine plants constructed in warm climates or combined power systems with a gas turbine, cooling of the compressor inlet air induces a need for additional power on top of the installed power $[8,9,10,11]$. In thermodynamic performance calculations for current combined power cycles, the calculations conducted with standard air assumptions are preferred for practical engineering purposes $[12,13]$.

The literature revealed that there was no previous study on a combines power system with a supercharged diesel cycle connected with a gas generator that works 
with a split shaft and the cooling of compressor inlet air and a low-pressure gas turbine [14]. There are several studies on diesel engine performance and theoretical diesel cycle models in the literature $[15,16,17]$. In the present study, a combined power cycle design was attempted based on the assumption that the selected diesel engine was adiabatic. The present study aim to calculate the thermodynamic availability and performance of the above-mentioned combined power system and to investigate the effects of atmospheric air cooling in the compressor inlet on the combined power system. [18] investigated the variations in the second law efficiency of gas turbines and their effects on the thermal efficiency of the combined cycle based on different gas turbine parameters. They reported that the exergy efficiency for different gas turbine operating parameters varied between $33.8 \%$ and $28.7 \%$ and the combined cycle thermal efficiency varied between $42 \%$ and $55 \%$ due to change in various parameters [18].

Energy, exergy and exergy economy in combined diesel engine power systems study was made by [19]. They introduced the formulas required to calculate energy exergy and exergy economy in each combined power system unit. They reported that the combined power systems that operate with compression ignition engines were among the most efficient simple cycle power generation plants and their efficiency was around $50 \%$.

Different methods to improve efficiency gas turbine cogeneration cycle are studied by [20]. In these methods, they investigated the increase in gas turbine inlet air temperature, cooling the compressor inlet air, air preheating, fuel preheating, increasing the compressor inlet air pressure, increasing the excess air rate, steam injection, and humidification of the compressor inlet air. They reported that exergy efficiency increased by $20 \%$ with efficiency improvement methods and they emphasized that, if possible, efficiency improvement methods should be applied together in combined power systems.

In the present study, a combined power cycle designed with a precooler, an intercooler, and a recuperator, and included a gas generator, a power turbine, and a diesel engine, was introduced. The current study aim to calculate the thermodynamic availability and performance of the introduced combined power cycle and to investigate the effects of intake air cooling at the compressor inlet on the combined power system.

It is found that the improvements in the first and second law efficiencies of the proposed models were significant and the recuperator application criterion was dependent on the rpk. The amount of fuel consumed in the gas turbine combustion chamber is reduced $10 \%$ with a comparison to the without pre-cooled combined cycle.

\section{MATERIAL AND METHODS}

\section{System Description}

The installation diagram of the system that included a diesel engine connected to a split shaft gas generator and a low-pressure turbine that utilized the waste energy of the exhaust gas and the compressor inlet air cooling unit is presented in Figure 1. The air drawn by the lowpressure compressor from the atmosphere is transferred through a pre-cooler, and the pressure is increased in the compressor and then passed through an intercooler and the air temperature was reduced to the atmospheric temperature and then a certain amount was sent to the high-pressure compressor and the remaining was sent to the diesel engine. The air, the pressure and temperature of which was increased in the high-pressure compressor was combined withthe fuel in the combustion chamber and the combustion of the fuel increases the air temperature up to the high-pressure turbine inlet temperature.

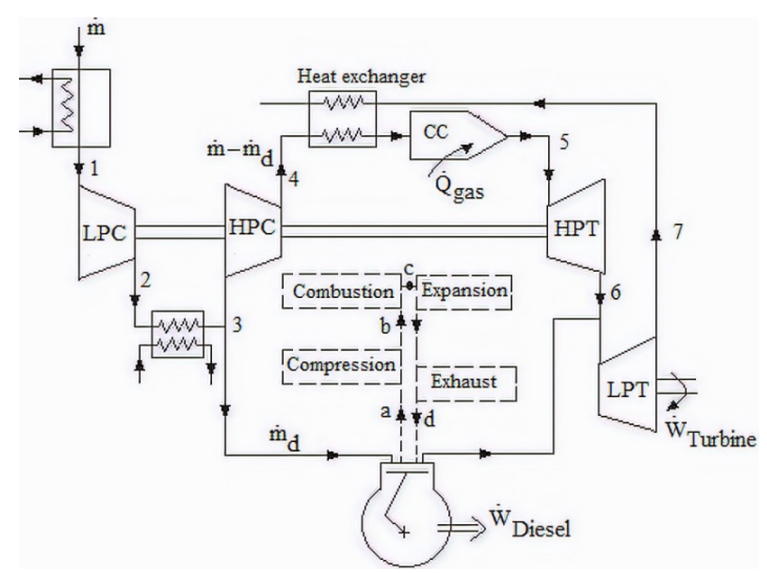

Figure 1. Brayton-diesel combined power system where the inlet air is cooled.

The combination of the air and the fuel in the diesel engine leads to an expansion due to the heat generated by combustion and produces power, and is mixed with the exhaust gases from the high-pressure turbine at the low-pressure turbine inlet and enters into the split-shaft low-pressure turbine and released to the atmosphere after expanding and producing power. The airflow completed by the lowpressure turbine is described as an open gas turbine cycle of the system in the literature [13]. In the present study, the thermodynamic model of the introduced system was developed based on thermodynamic air standard assumptions. It was assumed that the modeled diesel engine was adiabatic, and the cycle was an ideal diesel cycle. It was accepted that irreversibility in the gas turbine and the gas generator originated from compressors, turbines, combustion chamber, the mixture of air currents, pre-cooled and inter-cooled heat exchangers and recuperators. In gas turbine power units, it was reported in the literature that cooling the compressor 
intake air, especially in hot climate conditions, improved power generation. In the introduced system, quantitative and qualitative thermodynamic calculations were conducted to determine the effects of cooling the compressor intake air on system performance. Different techniques have been used in compressor intake air cooling. In the present study, it was considered to use an indirect evaporative air cooler. The aim of this study did not include investigating the effects of indirect evaporation air cooler performance on the introduced system. In the introduced system, the compressor and turbine connected to the diesel engine were not connected to the same shaft. Thus, the pressure of the supercharged air required by the diesel engine could be supplied directly from the low-pressure compressor. In the combined power system, the operating pressure of the diesel engine under supercharged conditions that corresponded to the values where the engine operated based on the turbocharged values was considered.

\section{Thermodynamic Model}

The ideal and irreversible processes of the combined cycle based on the station numbers indicated in the combined system installation scheme are presented in Fig. 1 and the introduced combine system cycle is presented in P-V and h-s diagrams in Fig. 2. The common cycle for the low- pressure turbine associated with the gas generator was a typical Joule-Brayton cycle. In the proposed model of the combined power system with and without air cooling at the compressor inlet, the volumetric flow of air that passes through the system remains constant The effects of air cooling in the compressor inlet on the combined system performance were also discussed. The cycles formed by the stations that defined the processes in the combined cycle under ideal operating conditions are $(a-b-c-d)$ and $(1-2 s-3-4 s-5-d-6 s-6 m-7 s)$.

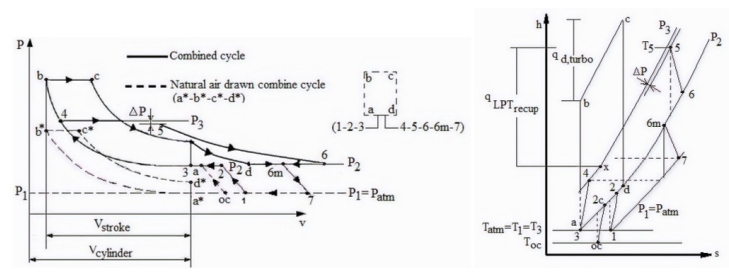

Figure 2. Combined power system $\mathrm{P}-\mathrm{v}$ and h-s diagrams

The cycle formed by the processes defined by irreversibility is (1-2-3-4-5-d-6-6m-7). The compressor inlet air cooling cycle varies (oc-2c-3-4-5-d-6-6m-7).

The properties of the diesel engine used in the system were obtained from the values of the diesel engine used as the main propulsion engine in the $\mathrm{RO}-\mathrm{RO}$ cargo ship named M/V ASSTAR TRABZON. The diesel engine was a 12-cylinder, four-stroke, $\mathrm{V}$ type engine with a nominal power of $2935 \mathrm{~kW}$ and a cylinder diameter $320 \mathrm{~mm}$ and a stro- ke length of $420 \mathrm{~mm}$ [21]. In the present study, the volumetric compression ratio was selected as 8 , the fuel cut-off ratio was selected as 2 and the rotation speed was selected as 600 rpm.The temperature and pressure values at the diesel cycle process stations and the cycle equations are given based on the compression and fuel cut-off rates are presented below:

Volumetric compression rate and fuel cut-off ratio

$$
r_{v}=\frac{v_{a}}{v_{b}}, r_{c}=\frac{v_{c}}{v_{b}}
$$

Temperature and pressure for isentropic compression are defined as below

$$
T_{b}=r_{v}^{k-1} T_{a}, P_{b}=r_{v}^{k} P_{a}
$$

Temperature and pressure at the end of the constant pressure heating

$$
T_{c}=r_{c} r_{v}^{k-1} T_{a}, P_{c}=P_{b}
$$

Temperature and pressure at the end of the isentropic expansion process

$$
T_{d}=r_{c}^{k} T_{a}, P_{b}=r_{c}^{k} P_{a}
$$

Mean effective pressure $P_{\text {mean }}$

$$
P_{\text {mean }}=\frac{P_{a} r_{v}^{k}\left[k\left(r_{c}-1\right)-r_{v}^{1-k}\left(r_{c}^{k}-1\right)\right]}{(k-1)\left(r_{c}-1\right)}
$$

The thermal efficiency of the diesel cycle was calculated with Eq. (6) [13].

$$
\eta_{d}=1-\left(\frac{1}{k}\right)\left(\frac{1}{r_{v}^{(1-k)}}\right)\left(\frac{r_{c}^{k}-1}{r_{c}-1}\right)
$$

Effective power equations for low and high-pressure compressors are given

$$
\dot{W}_{L P C}=\frac{\dot{m} c_{p}^{1-2}\left(T_{2 s}-T_{1}\right)}{\eta_{L P C}}, \dot{W}_{H P C}=\frac{\left(\dot{m}-\dot{m}_{d, \text { turbo }}\right) c_{p}^{3-4}\left(T_{4 s}-T_{3}\right)}{\eta_{H P C}}
$$

Effective power equations for low and high-pressure turbines are given below:

$$
\begin{aligned}
& \dot{W}_{H P T}=\left(\dot{m}-\dot{m}_{d, \text { turbo }}\right) c_{p}^{5-6}\left(T_{5}-T_{6 s}\right) \eta_{H P T}, \\
& \dot{W}_{L P T}=\dot{m} c_{p}^{6 m-7}\left(T_{6 m}-T_{7}\right) \eta_{L P T}
\end{aligned}
$$

The pressure loss in the combustion chamber is described with $\Delta \mathrm{P}$ and the inlet pressure for the high- pressure turbine is defined in Eq. (9).

$$
P_{T 5}=P_{3}\left(1-\varepsilon_{y}\right)
$$

$\varepsilon_{y}$ depicts the pressure loss percentage in Eq. (9)and varies between $\% 4$ and 6 . The exhaust gas pressure for the 
pressure loss in low-pressure turbine exhaust is defined below and $\psi_{\text {exp }}$ depicts the exhaust gas expansion loss coefficient and varies between 1.2 and 1.4.

$$
P_{\text {exhaust }}=\psi_{\exp } P_{\text {atm }}
$$

The calculations were conducted with the assumption that air exhaust pressure in the low-pressure turbine was $P_{6}=P_{\text {exhaust }}$. The mass flow of the air that passes through the low pressure compressor under atmospheric conditions was accepted as $m$ and the atmospheric conditions were accepted as ideal and the $\mathrm{z}$ is calculated with Eq. (11), the dimensionless energy equation for the gas generator. The defined $\mathrm{z}$ is a significant parameter that determines the high efficiency operating range of the designed cycle.

$$
(z-1) \theta \bar{c}_{p}\left(1-\frac{1}{\phi_{H P T}}\right) \eta_{H P T}=\frac{(z-1)\left(\phi_{H P T}-1\right)}{\eta_{H P K}}+z \frac{\left(\phi_{H P T}-1\right)}{\eta_{L P L K}}
$$

The dimensionless magnitudes in the equation above can be written as follows:

High-pressure turbine exponential pressure ratio $\phi_{H P T}$;

$$
\phi_{H P T}=\frac{T_{5}}{T_{6}}=\left(\frac{P_{T 5}}{P_{6}}\right)^{\frac{k-1}{k}}
$$

Low-pressure compressor pressure ratio $r_{p_{k 1}}$ and highpressure compressor pressure ratio $r_{p_{k 2}}$,

$$
r_{p_{k 1}}=\frac{P_{2}}{P_{1}}, \quad r_{p_{k 2}}=\frac{P_{3}}{P_{2}}
$$

Compressor unit pressure ratio:

$$
\begin{aligned}
& r_{p_{k}}=\frac{P_{3}}{P_{1}}, \phi_{L P C}=\frac{T_{2 s}}{T_{1}}=\left(r_{p_{k 1}}\right)^{\frac{k-1}{k}}, \\
& \phi_{H P C}=\frac{T_{4 s}}{T_{3}}=\left(r_{p_{k 2}}\right)^{\frac{k-1}{k}}, \phi_{K}=\phi_{L P C} \phi_{H P C}
\end{aligned}
$$

The ratio of the highest cycle temperature to atmospheric air temperature:

$$
\phi_{K}=\frac{T_{5}}{T_{1}}
$$

The ratio of specific temperatures at dimensionless constant pressure:

$$
\bar{c}_{p}=\frac{c_{p, \text { Turbine }}}{c_{p, \text { Compressor }}}
$$

Theoretical volumetric air flow rate $\dot{V}_{\text {cylinder }}$ and theoretical mass flow rate $\dot{m}_{d, \text { turbo }}$ in the diesel cycle:
$\dot{V}_{\text {cylinder }}=\operatorname{Vcylinder}\left(\frac{n}{2}\right)\left(\frac{1}{60}\right) \quad, \quad \dot{m}_{d, \text { turbo }}=\frac{P_{2} \dot{V}_{\text {cylinder }}}{R T_{3}}$

The ratio of theoretical mass airflow in the system $\dot{m}$, to the supercharged air mass flow in the diesel cycle, $\dot{m}_{d, \text { turbo }}$ is defined as z. $\mathrm{z}$ and theoretical air mass flow $\dot{V}_{\text {system }}$ in the system are given below,

$$
z=\frac{\dot{m}}{\dot{m}_{d, \text { turbo }}}, \dot{V}_{\text {system }}=\frac{\dot{m} R T_{a t m}}{P_{a t m}}
$$

The intake air temperature in the compressor inlet air cooling is calculated with $T_{o c}=x T_{a t m}$ this equation. Where $\mathrm{x}$ is the ratio of the intake air cooling temperature to the atmospheric air temperature and could vary between 0.85 and 0.99 and could be applied technologically. Volumetric flow air inlet temperature in the system remains constant with or without cooling; thus, the mass flow of the air in the precooled cycle can be calculated with the following equation:

$$
\dot{m}_{o c}=\frac{P_{a t m} \dot{V}_{s y s t e m}}{R T_{o c}}
$$

The following equation could be written for the mass air flows in pre-cooled and without pre-cooled cycles:

$$
\dot{m}_{o c}=\frac{1}{x} \dot{m}
$$

The changes in average specific temperatures of the air in isentropic compression and expansion in pre-cooled and without pre-cooled cycles are negligible. The thermal efficiency of the cycle can be written as follows:

$$
\eta=\frac{\dot{W}_{d, \text { turbo }}+\dot{W}_{L P T}}{\dot{Q}_{d, t u r b o}+\dot{Q}_{g a s}}
$$

where,

$$
\begin{aligned}
& \dot{Q}_{d, \text { turbo }}=\dot{m}_{d, \text { turbo }} c_{p}^{b-c}\left(T_{c}-T_{b}\right), \\
& \dot{W}_{d, \text { turbo }}=\eta \dot{Q}_{d, \text { turbo }} \text { and } \dot{Q}_{\text {gas }}=m c_{p}^{5-4}\left(T_{5}-T_{4}\right)
\end{aligned}
$$

The thermal efficiency of the cycle with compressor intake air cooling was calculated with the equation below;

$$
\eta_{o c}=\left[\frac{\dot{W}_{d, t u r b o}+\dot{W}_{L P T}}{\dot{Q}_{d, t u r b o}+\dot{Q}_{g a s}}\right]_{o c}
$$

The equations used in the air pre-cooling operation are similar to the equations used with the cycles without air pre-cooling and the cooling effects of the atmospheric air were included in these equations. 


$$
\begin{gathered}
\eta_{I_{\text {reaup }}}=\frac{\dot{W}_{d, \text { turbo }}+\dot{W}_{L P T}}{\left(\dot{m}-\dot{m}_{d, \text { turbo }}\right) c_{p_{5}} T_{5}-\left(\dot{m}-\dot{m}_{d, \text { turbo }}\right) c_{p_{T x}} T_{x}+\dot{Q}_{d, \text { turbo }}} \\
\eta_{I_{\text {recup }, o c}}=\frac{\dot{W}_{d, \text { turbo }}+\dot{W}_{L P T, o c}}{\left(\dot{m}_{o c}-\dot{m}_{d, \text { turbo }}+\dot{m}_{y g a s, o c}\right) c_{p_{5}} T_{5}-\left(\dot{m}_{o c}-\dot{m}_{d, \text { turbo }}\right) c_{p_{T X}} T_{x}+\dot{Q}_{d, \text { turbo }}}
\end{gathered}
$$

The mass fuel flow in the diesel engine and the gas turbine was determined with the following equations. LHV depicts the thermal value of the fuel.

$$
\dot{m}_{y_{d, \text { turbo }}}=\frac{\dot{Q}_{d, \text { turbo }}}{L H V-c_{p_{b-c}} T_{c}}, \dot{m}_{y_{g a s}}=\frac{\dot{Q}_{d, \text { turbo }}}{L H V-c_{p_{4-5}} T_{5}}
$$

Total fuel consumption in the combined system was calculated with the equation below:

$$
\dot{m}_{y}=\dot{m}_{d, \text { turbo }}+\dot{m}_{y_{\text {gas }}}
$$

Where $\psi$ depicts the ratio of the mass flow rate of the fuel utilized in the turbine combustion chamber to total fuel consumption mass flow rate and calculated with the following equation:

$$
\psi=\frac{\dot{m}_{y_{g a s}}}{\dot{m}_{y}}
$$

The fuel consumption remains the same in fuel calculation for the cycle with pre-cooling. The following equation was used to determine the ratio of the system air mass flow rate to the total system fuel consumption:

$$
\mu=\frac{\dot{m}}{\dot{m}_{y}}, \beta=\frac{\dot{m}_{y}}{\dot{m}}
$$

Since the mass airflow rate remains the same in the diesel cycle in the combined cycle, the fuel mass flow rate in the diesel cycle would also remain constant. In the diesel cycle, the air compression pressure may be high; however, the baseline compression temperature is reduced to the atmospheric pressure through the intercooler. In the theoretical cycle, the highest cycle temperature depends on the volumetric compression ratio of the cycle and the fuel cutoff rate and is directly proportional to the inlet temperature.

$$
\begin{aligned}
& \dot{m}_{y_{d, \text { turbo }}}=\frac{\dot{Q}_{y_{d, \text { urbo }}}}{L H V-c_{p_{b c}} T_{c}}, \quad \dot{m}_{y_{g a s, o c}}=\frac{\dot{Q}_{g a s, o c}}{L H V-c_{p_{4-5}} T_{5}} \\
& \dot{m}_{y_{o c}}=\dot{m}_{y_{d, \text { turb }, o c}+\dot{m}_{y_{g a s, o c}},} \\
& \dot{m}_{y_{\text {saving }}}=\left(\dot{m}_{y_{d, \text { turbo }}}-\dot{m}_{y, \text { recup }}\right) 100 / \dot{m}_{y_{d, \text { turbo }}}
\end{aligned}
$$

\section{Exergy Analysis}

The second law analysis in thermodynamics is a powerful tool in the optimization of complex power systems. Exergy, also known as usability, is the portion of energy that could be utilized. In the present study, the exergy of air at each system unit inlet was calculated with the following equation [13]:

$$
e=c_{p}\left(T_{1}-T_{o}\right)-T_{o}\left[c_{p} \ln \left(\frac{T_{1}}{T_{o}}\right)-R \ln \left(\frac{P_{1}}{P_{o}}\right)\right]
$$

In the Brayton-diesel combined power system, where the intake air is cooled and shown in Fig. 1, the mass, energy, and exergy balance equations for each system component are presented in Table 1 . In exergy calculations, the temperature was accepted as $25^{\circ} \mathrm{C}$ and the pressure was accepted as $1 \mathrm{~atm}$ for the dead state condition.

Since the temperatures remain constant in decomposition, pressure losses lead to irreversibility. The second law of thermodynamics efficiency equations for the pre-cooled and without pre-cooled systems is given in Eq. (33) and Eq. (34). The second law of thermodynamics efficiency for the recuperator system is given in Eq. (35).

$$
\begin{aligned}
& \eta_{I I}= \\
& \dot{E}_{Q_{d, \text { turbo }}+\dot{W}_{L P T}}+\dot{m} e_{1}+\dot{E}_{Q_{C b}}+\left(\dot{m}-\dot{m}_{d, \text { turbo }}+\dot{m}_{y, g a s}\right) e_{5}+\left(\dot{m}_{d, \text { turbo }}+\dot{m}_{y, \text { diesel }}\right) e_{3}
\end{aligned}
$$

$$
\begin{aligned}
& \eta_{I I, o c}= \\
& \frac{\dot{W}_{y_{d, \text { urbo }}}+\dot{W}_{L P T}}{\left.\dot{E}_{Q_{d, \text { urto }}}+\dot{m}_{o c} e_{1}+\dot{E}_{Q_{C b}}+\left(\dot{m}_{o c}-\dot{m}_{d, \text { turbo }}+\dot{m}_{y, \text { gas }}\right)\right) e_{5}+\left(\dot{m}_{d, \text { turbo }}+\dot{m}_{y, \text { diese } e_{o c}}\right) e_{3}}
\end{aligned}
$$

$$
\eta_{I_{\text {recup }}}=\frac{\dot{W}_{y_{d, \text { turbo }}}+\dot{W}_{L P T}}{\dot{E}_{Q_{d, \text { turbo }}}+\dot{E}_{Q_{c b}}+\left(\dot{m}-\dot{m}_{d, \text { turbo }}+\dot{m}_{y, \text { gas }}\right) e_{5}}
$$

The second law efficiency of the cycle with pre-cooling and recuperator is given below:

$$
\eta_{I_{I_{\text {recup }}}}=\frac{\dot{W}_{y_{d, \text { turbo }}}+\dot{W}_{L P T, o c}}{\dot{E}_{Q_{d, \text { turbo }}}+\dot{E}_{Q_{C b}}+\left(\dot{m}-\dot{m}_{d, \text { turbo }}+\dot{m}_{y, \text { gas }}\right) e_{5}+\dot{E}_{Q_{\text {preccoling }}}}
$$


Table 1. Mass, energy and exergy equations for system components

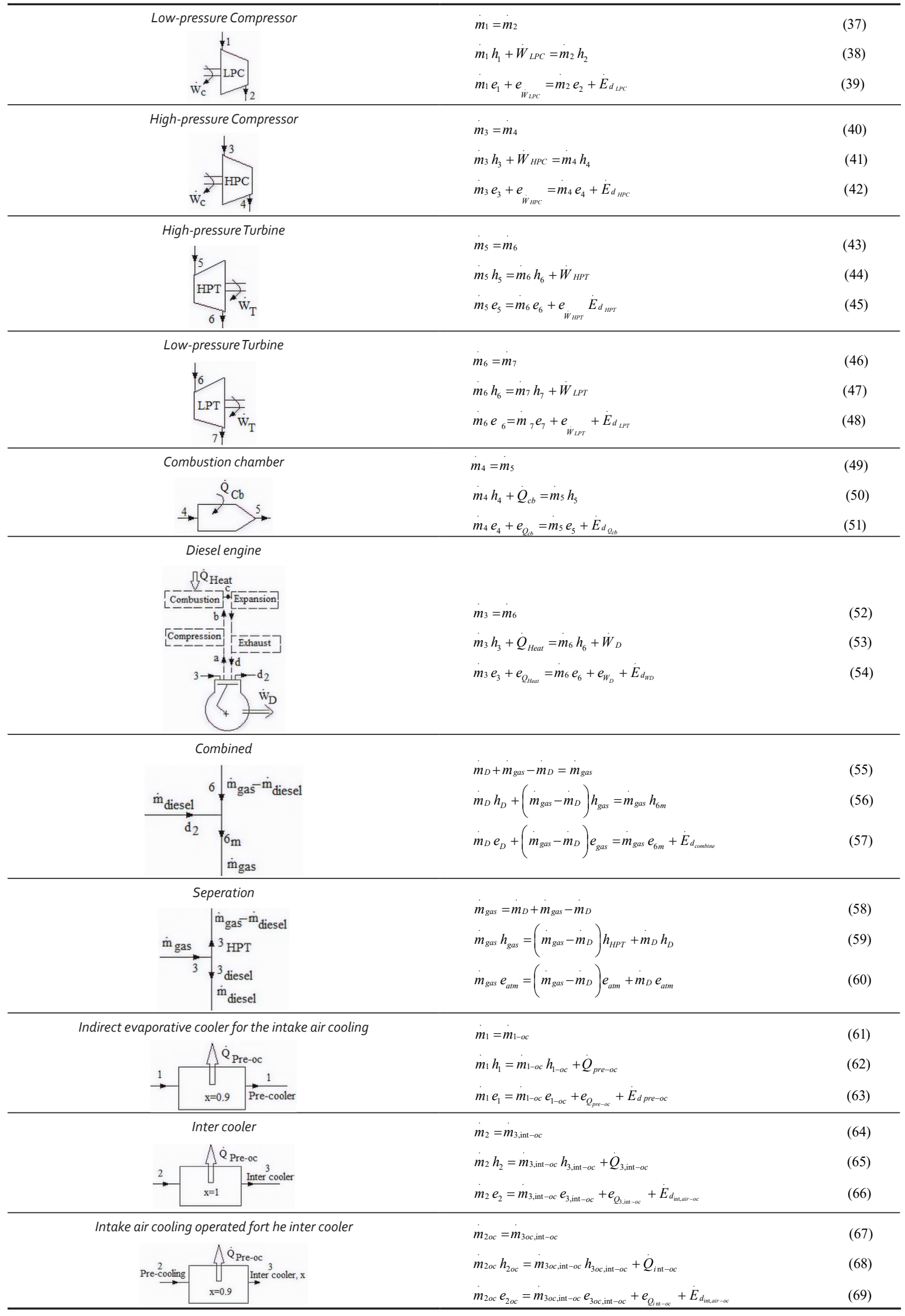




\section{RESULTS AND DISCUSSION}

The power generated in the combined system and the increase in the compressor unit pressure affect the power generated in the low-pressure turbine. The compressor unit was therefore considered as two stages. However, since the low-pressure compressor pressure, $r_{p k 1}$, was limited by the limit values under the supercharged conditions of the diesel cycle, the performance of the combined system was scrutinized based on the changes in this parameter.

The limit power values that could be obtained in the combined system in the $r_{p k 1}$ increases based on the selected $r_{p k}$ values are presented in Fig. 3 .
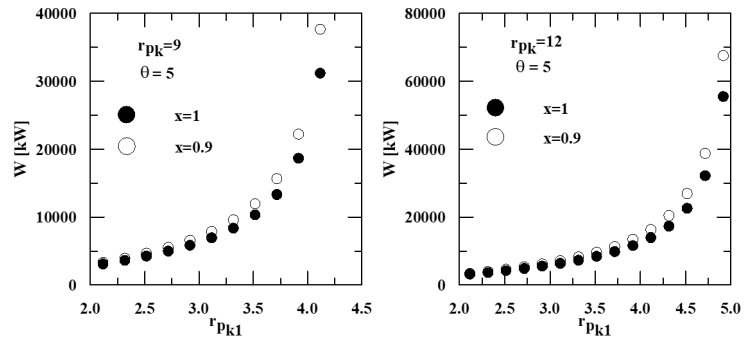

Figure 3. The change in the combined power system in various $r_{p k}$ values based on power and low-pressure compressor $r_{p k 1}$ pressure ratio.

The power generated in the combined system is directly associated with the mass flow rate of the air circulating in the system. Therefore, the power generated in the combines system is based on the design of the gas turbine group in addition to the power of the selected diesel engine. In the present study, the turbocharged diesel unit (lowpressure compressor and low-pressure turbine) operating with a split shaft, and a high-pressure turbine group (gas generator) that drives the compressors were modeled as a combined system. As seen in Fig. 3, the decrease in the combined system pressure (P3/P1) leads to a decrease in the generated power, which is directly associated with the mass flow of the air circulating in the system and decreases at this value. However, the supercharged operating conditions of the diesel engine determine a low-pressure compressor ratio $r_{p k 1}$ for each $r_{p k}$ value. It is possible to observe the performance of the intake-air-cooled combined systems based on the cooling efficiency parameter $\mathrm{x}$ in the same figures. Here, the magnitude and significance of the effect of intake-air cooling on power generation could be observed. For $r_{p k 1}=3.5$, the increase in power increase was about $15 \%$. The difficulty of the implementation of $\mathrm{x}=0.8$ value determined in the present study is obvious.

As seen in Fig. 4, the thermal efficiency of the combined system also reached a maximum value based on the pressure ratio of the low-pressure compressor in the intake air cooled combined system too. In contrast, the thermal efficiency of the inlet air-cooled composite system decreased as the low pressure compressor pressure ratio $r_{p k 1}$ increased. Similarly, the lower the pressure ratio of the compressor unit the lower the thermal efficiency of the combined system. Based on the same figures, it was determined that the use of a recuperator increased the thermal efficiency in the combined cycle with a recuperator and with and without intake-air cooling; however, it did not effect on the thermal efficiency when the compressor unit pressure was lower than a certain value $\left(r_{p k}=7\right)$.
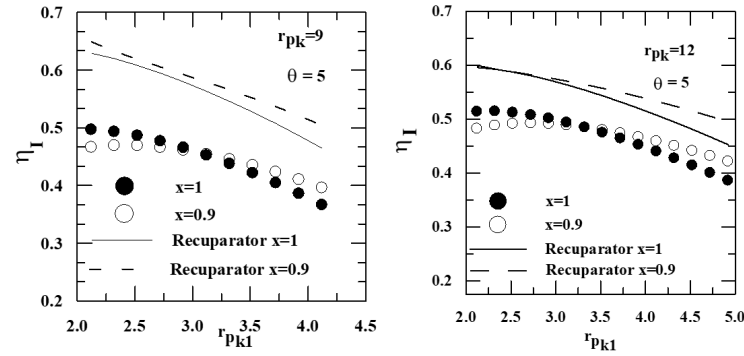

Figure 4. The variations in the combined power system based on thermal efficiency in various $r_{p k}$ values and low-pressure compressor $r_{p k 1}$ , pressure ratio.
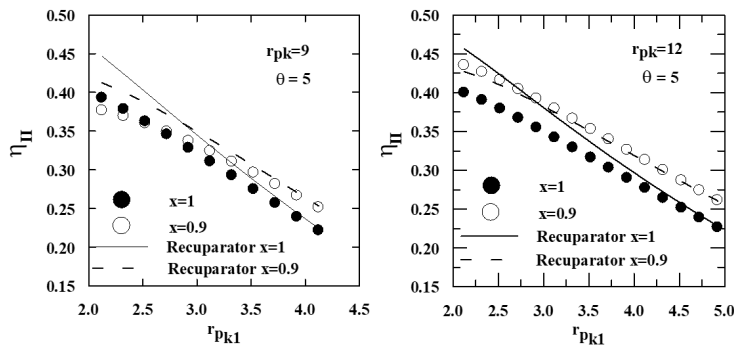

Figure 5. The variations in the combined power system based on exergy efficiency in various $r_{p k}$ values and low-pressure compressor $r_{p k 1}$ pressure ratio.

In Fig. 5, the low-pressure compressor also decreased with the increase in pressure ratio $r_{p k 1}$ in the proposed model introduced in the second law efficiency of the combined system. The change in the total fuel consumption mass flow rate in the combined system based on $r_{p k 1}$ is presented in Fig. 6. The total fuel mass flow rate is presented in Fig. 6 for $r_{p k}$ values of 9 and 12 where it was higher for each $r_{p k 1}$ value when compared to other proposed models with intake air cooling. Similar variations were identified for other compressor pressure ratios as well.
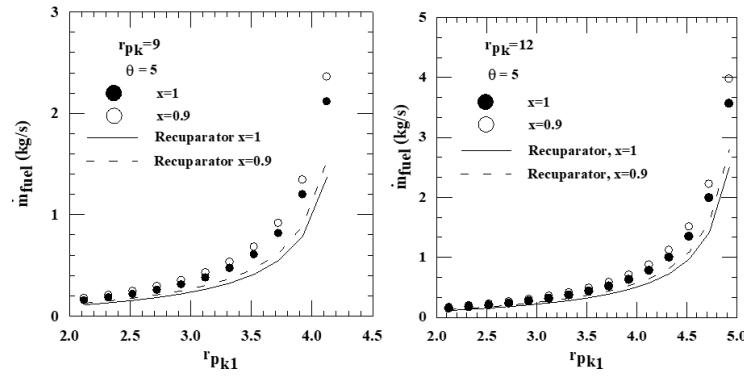

Figure 6. The variations in $r_{p k 1}$ with fuel mass flow for $r_{p k}=9$ and $r_{p k}=12$ in combined power system 
The increase in generated power with the increase in fuel/air ratio $\beta$ for each $r_{p k}$ value in the combined system is presented in Fig. 7.
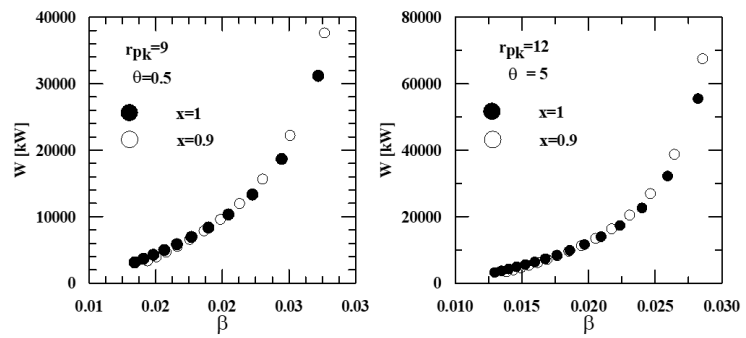

Figure 7. The variations in fuel/air ratio $\beta$ for various $r_{p k}$ values in the combined power system

The variations in thermal efficiency for various $r_{p k}$ values in the air pre-cooled and without pre-cooled combined power systems based on the air-fuel ratio are presented in Fig. 8.
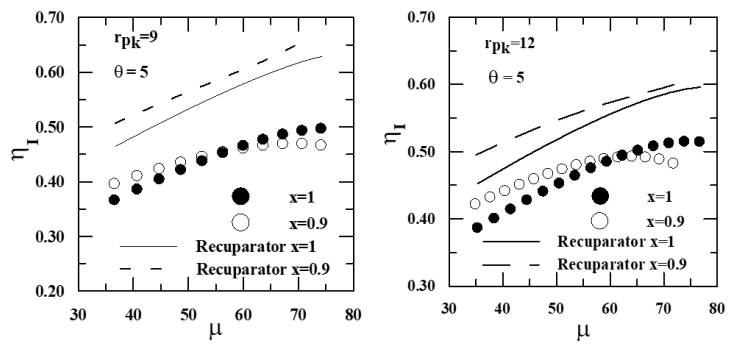

Figure 8. The variations in thermal efficiency for various $r_{p k}$ values in the combined power systems based on the air-fuel ratio

In Fig. 9, it was observed that the low-pressure compressor increased with the increase in the pressure ratio $\mu$ in the operating modes introduced in the second law efficiency of the combined system.
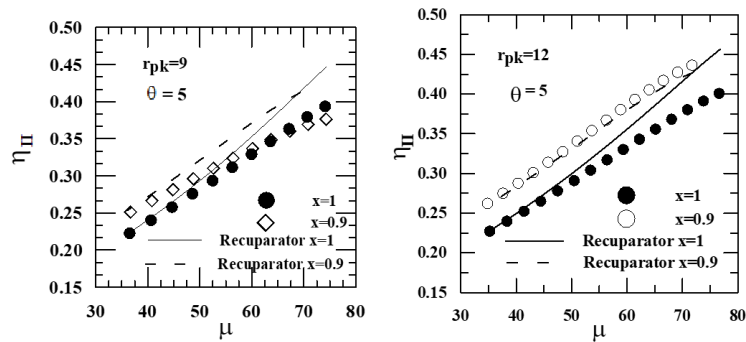

Figure 9. The changes in exergy efficiency and air/fuel ratio in the combined power system for various $\mu$ values

The variations in average effective pressure with $r_{p k 1}$ in the diesel engine are presented in Fig. 10. Based on the figure, the power was directly proportional to the supercharging pressure. The changes in the ratio of the fuel mass flow rate in the turbine combustion chamber to the total fuel consumption mass flow rate based on $r_{p k 1}$ are presented in Fig. 11. The review of Fig. 12 demonstrated that recuperator use was beneficial for fuel efficiency in all proposed models.
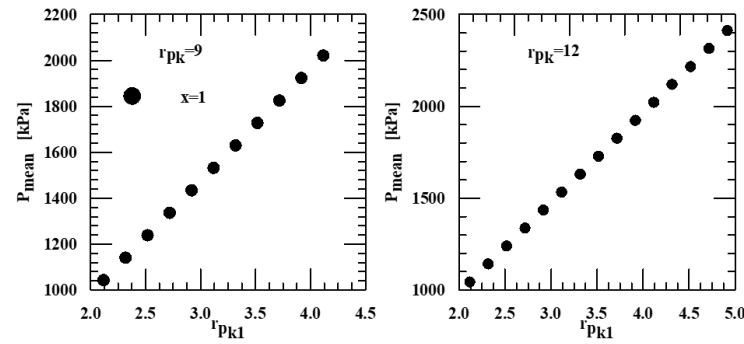

Figure 10. The variations in average effective pressure with $r_{p k 1}$ in the diesel engine
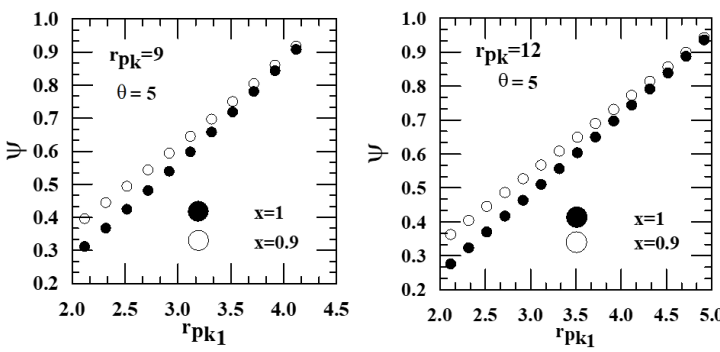

Figure 11. The ratio of the mass flow rate of the fuel used in the turbine combustion chamber to the mass flow rate of the total fuel consumption, change according to $r_{p k}$
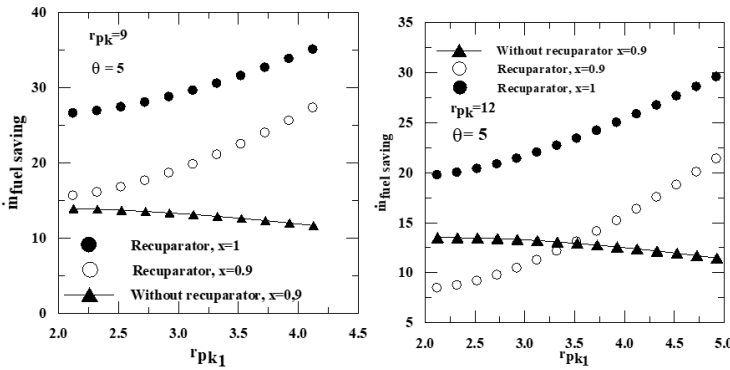

Figure 11. Fuel savings for $r_{p k}$ values in the combined system variation with respect to $r_{p k 1}$

\section{CONCLUSION}

In the introduced combined cycle, it was demonstrated that the inlet air was an effective solution to meet the peak power requirements in hot climate conditions.It was also demonstrated that the air pressure required for the supercharge operation in the diesel engine could be supplied by a compressor unit. The first of the compressor groups utilized in the combined cycle was the lowpressure compressor and it was demonstrated that the use of the diesel exhaust mixture of the gas generator energy waste in the low-pressure turbine increased the power generated by the combined system when the pressure rate is selected to prevent the combustion in diesel engine supercharge conditions. It was observed that the generated power increased under the highest pressure and atmospheric pressure conditions used in the cycle at higher $r_{p k}$ values; however, the limit values of the generated power reached the optimum value under the diesel engine supercharged combustion conditions that limited 
$r_{p k 1}$ pressure ratio. In contrast, the efficiency of the combined cycle decreased with an increase in $r_{p k 1}$.

The second law efficiency of the combined system exhibited a decrease with the increase in the low-pressure compressor pressure ratio. The increase in $r_{p k 1}$ led to supercharge in the diesel cycle, hence to an increase in irreversibility, increasing the exergy destruction in the high-pressure compressor, combustion chamber, exhaust gas mixture, and low-pressure turbine, leading to a decrease in the second law efficiency of the combined cycle.

It was observed that the compressor intake-aircooling increased power generation in the combined power system with compressor inlet air cooling, and it increased the second law efficiency, although it had no significant impact on the first law efficiency.

In cycle models with a recuperator, the improvements in the first and second law efficiencieswere significant and the recuperator application criterion was dependent on the $r_{p k}$. The maximum average effective pressure achievable in the diesel engine is around $2500 \mathrm{kPa}$.The amount of fuel consumed in the gas turbine combustion chamber in the pre-cooled combined cycle was approximately $10 \%$ higher when compared in the without pre-cooled combined cycle.

The use of a recuperator in the combined cycle could provide increased fuel saving based on the $r_{p k 1}$ values in the combined system. Furthermore, the fuel-saving in the precooled cycle was at the lowest values.

\section{SYMBOLS}

$\mathrm{C}_{\mathrm{p}} \quad$ Specific heat at constant pressure $[\mathrm{kJ} / \mathrm{kgK}]$

$\mathrm{C}_{\mathrm{v}} \quad$ Spesific heat at constant volume $[\mathrm{kJ} / \mathrm{kgK}]$

exp Expantion

$\dot{m} \quad$ Mass of flow rate $[\mathrm{kg} / \mathrm{s}]$

$\mathrm{R} \quad$ Gas constant for air $[\mathrm{kJ} / \mathrm{kgK}]$

$r_{p} \quad$ Pressure ratio

$\mathrm{T} \quad$ Temperature[K]

P Pressure[Pa]

$\dot{W} \quad$ Power $[\mathrm{kW}]$

$\eta \quad$ Efficiency[\%]

$\theta \quad$ The ratio for the turbine inlet temperature to the athmosperic air temperature

$\varepsilon_{\mathrm{y}} \quad$ Pressure loss in percentage

$\psi \quad$ Expantion coefficient for exhaust gas

$\mathrm{x} \quad$ The ratio for the cooling air temperature to the athmospheric air temperature

ABK Low-pressure compressor

YBK High-pressure compressor

$\begin{array}{ll}\text { HPT } & \text { High-pressure turbine } \\ \text { LPT } & \text { Low- pressure turbine } \\ \text { atm } & \text { Atmospher } \\ \mathrm{D} & \text { Diesel } \\ \text { Int } & \text { Inter } \\ \mathrm{k} & \text { The ratio of the specific heats } \\ \text { oc } & \text { Cold air } \\ \text { recup } & \text { Recuparator } \\ \text { turbo } & \text { Turbocharge } \\ \mathrm{y} & \text { Fuel } \\ \mathrm{Cb} & \text { Combustion chamber }\end{array}$

\section{References}

1. Khana MN, Tlilib I. New advancement of high performance for a combined cycle power plant: Thermodynamic analysis. Case Studies in Thermal Engineering 12 (2018) 166-175.

2. Descombes G, Boudigues S. Modelling of waste heat recovery for combined heat and power applications. Applied Thermal Engineering Elsevier 29, 13 (2009) 2610. 10.1016/j.applthermaleng.2008.09.019.

3. El-Awad MM, Siraj MA. A Combined Diesel-Engine Gas-TurbineSystem for Distributed Power Generation. International Conference on Chemical, Biological and Medical Sciences (ICCBMS), Kuala Lumpur Malaysia, 2012

4. Altosole M, Benvenuto G, Campora U, Laviola M, Trucco A. Waste Heat Recovery from Marine Gas Turbines and Diesel Engines, Energies. 10 (2017) 1-24.

5. Dzida M, Mucharski J. On the possible increasing of efficiency of ship power plant with the system combined of marine diesel engine, gas turbine and steam turbine in case of main engine cooperation with the gas turbine fed in parallel and the steam turbine. Polish maritime research. 16 (2009) 40-44.

6. Durmusoglu Y, Kocak G. Exergetic efficiency analysis of a combined power plant of a container ship. Journal of Thermal Engineering, 5 (2019) 1-13.

7. Dzida M. Possible efficiency increasing of ship propulsion and marine power plant with the system combined of marine diesel engine, gas turbine and steam turbine. Advances in Gas Turbine Technology. (2011) pp. 45-68. DOI:10.5772/24018.

8. Al Madani H. Gas turbine performance enhancement by intake air cooling. International Journal of Exergy, 3 (2006) 164-173.

9. Ibrahim TK, Rahman MM, A Abdalla N. Improvement of gas turbine performance based on inlet air cooling systems: A technical review. International Journal of Physical Sciences. 6 (2011) 620-627.

10. Kumar A., Sanjay M. and Prasad L. Parametric analysis of cooled gas turbine cycle with evaporative inlet air cooling. International Journal of Scientific \& Engineering Research. 3 (2012) 3, 1-8.

11. Zaki GM, Jassim RK, Alhazmy MM. Energy, exergy and thermoeconomics analysis of water chiller cooler for gas turbines intake air cooling. Smart Grid and Renewable Energy. 2 (2011) 190-205. 
12. Stone R. Introduction to Internal Combustion Engines. The Mac Millan Press LMTD. 1992.

13. Çengel YA, Boles BA. Thermodynamics and Engineering Approach. McGraw Hill-Science, 6th edition. 2001.

14. Mohammadkhani F, Khalilarya SH, Mirzaee I. 2012. Energetic and Exergetic Analysis of Internal Combustion Engine Cogeneration System. The Journal of Energy: Engineering \& Management. 2 (2012) 4 24-31.

15. Reddy S.S.K., Pandurangadu V. and S.P.A. Hussai S.P.A Effect of turbo charging on volumetric efficiency in an insulated diesel engine for improved performance. International Journal of Modern Engineering Research (IJMER). 3, (2013) 2 674-677.

16. Ebrahimi R. Thermodynamic modelling of performance of an irreversible Diesel cycle with engine speed, ature and Science. 7 (2009) 9 78-82.

17. Qian JY, Zhang Y, Zhuge W. Air supply system design of a diesel_brayton combined cycle. Proceedings of the Institution of Mechanical Engineers, Part A:
Journal of Power and Energy. (2018) https://doi. org/10.1177/0957650918810133

18. Sreedharan H, Reshma JR, Jacob JK, Sivakumar VV. Energy and exergy analysis on $350 \mathrm{MW}$ combined cycle power plant. European Journal of Technology and Design. 12 (2016) 2 72-78.

19. Abuşoğlu A, Kanoğlu M. Exergetic and thermoecomnomic analyses of diesel engine powered cogeneration: Part 1Formulations. Journal of Applied Thermal Engineering. 29 (2009) 234-241.

20. Karali R, Öztürk iT. Effiency improvement of gas turbine cogeneration systems. Improving the efficienc of gas turbine cogenartion systems. Technical gazette 25 suppl 1 (2017), 21-27. DOI: 10.17559/TV-20140509154652

21. Karaca, S. 2015. Application of energy and exergy analysis due to different angles of propeller blades to a turbocharged diesel engine vessel. Master thesis. Karadeniz Technical Iniversity, Trabzon. 